\title{
Françoise Choay, Le patrimoine en questions : anthologie pour un combat
}

Paris, Seuil, la couleur des idées, 2010, 220 p., index.

\section{(2) OpenEdition}

Journals

Édition électronique

URL : http://journals.openedition.org/dht/1873

DOI : 10.4000/dht.1873

ISSN : 1775-4194

Éditeur :

Centre d'histoire des techniques et de l'environnement du Cnam (CDHTE-Cnam), Société des élèves du CDHTE-Cnam

\section{Édition imprimée}

Date de publication : 1 décembre 2011

Pagination : 248-249

ISBN : 978-2-9530779-7-1

ISSN : 0417-8726

Référence électronique

André Guillerme, "Françoise Choay, Le patrimoine en questions : anthologie pour un combat »,

Documents pour I'histoire des techniques [En ligne], 20 | 2e semestre 2011, mis en ligne le 21 septembre 2012, consulté le 21 septembre 2020. URL : http://journals.openedition.org/dht/1873 ; DOI : https:// doi.org/10.4000/dht.1873

Ce document a été généré automatiquement le 21 septembre 2020.

(c) Tous droits réservés 


\section{Françoise Choay, Le patrimoine en questions : anthologie pour un combat}

Paris, Seuil, la couleur des idées, 2010, 220 p., index.

André Guillerme

\section{RÉFÉRENCE}

Françoise Choay, Le patrimoine en questions : anthologie pour un combat, Paris, Seuil, la couleur des idées, 2010, 220 p., index. 
1 Cinquante pages combattant, cent cinquante défendant: l'œuvre de Françoise Choay est un traité de poliorcétique patrimoniale et un précieux recueil pédagogique, emblématique, qui introduit une douzaine de textes fondamentaux relatifs aux monuments historiques. On y fait la genèse $d u$ monument historique défini comme « dispositif mémoriel intentionnel ». Cette pièce à conviction appartient d'abord à la culture ouest-européenne. Elle démarre et prend de l'amplitude dans deux lieux de mémoire. La première révolution culturelle qui se manifeste en Italie d'abord parce qu'il y a là un milieu - une concentration de monuments romains, d'antiquités. On y trouve en outre, à la Renaissance, un relâchement du

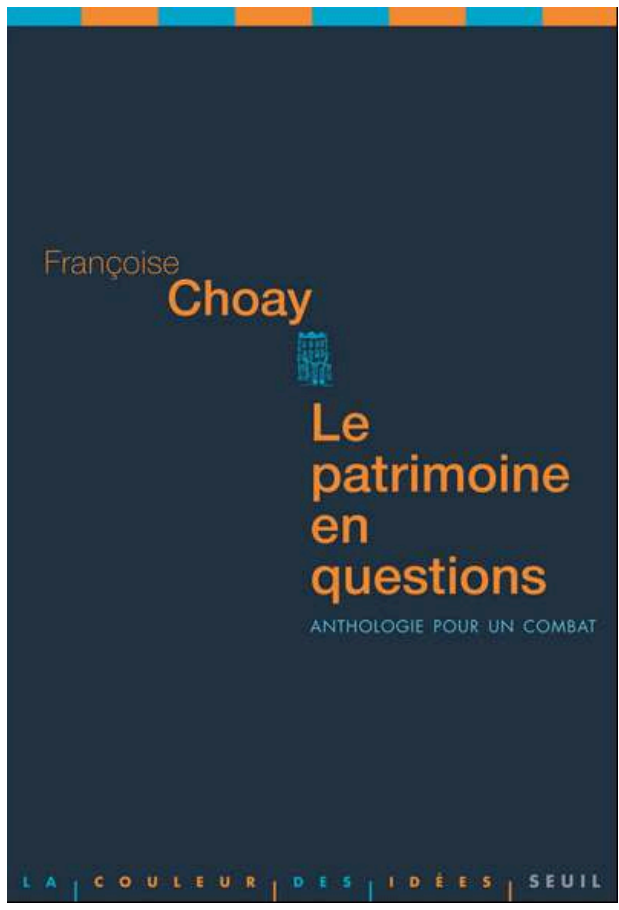
théocentrisme selon Eugenio Garin, ou un déploiement de l'incroyance selon Lucien Febvre. On y trouve encore des porteurs - des supporters: les antiquaires, érudits, collectionneurs, scripteurs, esthétisants. La seconde révolution culturelle éclot en Angleterre, à la fin du XVIIIe siècle, parce que la sombre industrie détourne le regard romantique des élites vers les témoins de l'Histoire - qui se rationalise pour devenir une discipline humaniste. Cette double révolution culturelle met l'Europe en branle, muséifie et restaure selon deux doctrines : la façon «path dependance » de Ruskin et celle "état pristine » de Viollet-le-Duc. Dès lors, le patrimoine gagne les pays voisins pour forger leur vision du monde, puis de loin en loin couvre la planète à la fin du XXe siècle. Héritage ou patrimoine, économie ou société, qualité et défaut ou qualité seulement : deux partis dont les avocats font effets de manche dans les instances internationales chargées de ce que Françoise Choay désigne par « fétichisation » des monuments.

2 La rétrospective qui suit vise le patrimoine de demain géré par la « révolution électrotélématique" qui accorde bien trop d'hégémonie aux techniques ( $p$. XXXIII). La réticularisation de l'espace banalise le monumental, tandis que le tourisme de masse promu par les organes internationaux de culture se consomme dans des lieux « invraisemblables », copies de monuments, sans mémoire. Une mise en garde plus que nécessaire aujourd'hui. Pour pallier, Françoise Choay vise trois objectifs: enseigner enfin l'histoire de l'art dans les collèges et lycées, réapproprier culturellement et localement les monuments historiques, leur donner sens, en faire somme toute un paysage.

L'anthologie

4 Une quinzaine de pages pour le primius inter pares, l'abbé de Saint Denis, Suger. Son savoir et son art en font une figure tutélaire révélés par Erwin Panovsky dans sa belle Architecture médiévale et pensée scolastique à propos de la naissance du gothique. Les extraits des deux Mémoires de Suger, sur la conservation de l'abbaye et l'administration de la fabrique nous informe de ce que l'abbé estime devoir être 
protégé ou restauré, de ce qu'il saisit de l'architecture religieuse : un phylactère dédié au spirituel. Une esthétique proche de celle de Thomas d'Aquin à laquelle Umberto Eco nous a sensibilisés.

5 Suivent des morceaux choisis du Poge, de Pie II et de Jacob Spon, médecin antiquaire dont sont extraits des Voyages (1675) en Italie, Dalmatie et Grèce, rappelant les risques des voyages et décrivant quelques antiquités. Puis, suivant la chronologie, vient la préface de L'Antiquité expliquée et représentée en figure (1719) de Montfaucon, autre célèbre antiquaire, érudit, consciencieux : « apercevoir des changements que le temps a apportés à toutes ces choses» (p. 74). La période révolutionnaire est représentée par Millin, inventeur du "monument historique ", fragile ouvrage qui permet à l'esprit humain de «s'avancer sensiblement vers la perfection» (p. 80), et surtout Vic d'Azyr, médecin et humaniste, urbain et humain, co-fondateur de la Société de médecine qui instruit une manière d'inventorier et de conserver... Tous les objets qui peuvent servir aux arts, aux sciences et à l'enseignement (1794), véritable logiciel des connaissances matérielles dont on trouve les prémices dans le modèle d'enquête des topographies médicales destinées au bien public. Ce splendide tableau encyclopédique fait long feu puisqu'il sert quarante ans plus tard à Guizot pour créer l'inspection des monuments historiques. Les Considérations morales sur la destination des ouvrages de l'art de Quatremère de Quincy (1815) puis «La guerre aux démolisseurs" (1825) précèdent "Ceci tuera cela » de Notre-Dame de Paris (1832) du jeune Victor Hugo qui marque le dépassement de l'écriture par le monument. Les sept lampes de l'architecture de Ruskin (1849) et «Entretien et restauration des cathédrales de France » de Viollet-leDuc (1851) montrent clairement les points communs et les oppositions de ces deux doctes maitres d'œuvre. Riegl, le premier à opposer, en 1903, monument à monument historique, est bien présent, comme "L'urbanisme face aux villes anciennes » de Giovannoni (1913) et "La conservation des monuments d'art et d'histoire » de la Conférence d'Athènes (1933). Enfin, les interventions parlementaires d'André Malraux (1960-62) - « Nos monuments sont le plus grand songe de la France ». La Conférence de Venise (1964) et la Convention de l'UNESCO (1972) sont des textes difficiles à trouver mais indispensables à la pédagogie du patrimoine matériel.

Plus qu'une anthologie, c'est une chronique concise de témoignages savants quant à la collecte matérielle et immatérielle de traces, de vestiges, de mémoires.

\section{AUTEURS}

\section{ANDRÉ GUILLERME}

CDHTE-Cnam 